\title{
TEN-YEAR EXPERIENCE WITH THE CARPENTIER-EDWARDS PERICARDIAL XENOGRAFT IN THE TRICUSPID POSITION
}

Kiyoharu Nakano, MD ${ }^{\mathbf{a}}$

Kiyoyuki Eishi, MD

Yoshio Kosakai, MD

Fumitaka Isobe, $\mathrm{MD}^{\mathrm{a}}$

Yoshikado Sasako, $\mathrm{MD}^{\mathrm{a}}$

Seiki Nagata, $\mathrm{MD}^{\mathrm{b}}$

Hatsue Ueda, $\mathrm{MD}^{\mathrm{c}}$

Yoshitsugu Kito, $\mathrm{MD}^{\mathrm{a}}$

Yasunaru Kawashima, MD
We reviewed the cases of 66 patients who underwent 67 tricuspid valve replacements with Carpentier-Edwards pericardial xenografts between April 1985 and January 1994. Average patient age at time of operation was 52 years (range 8 to 71 years). Concomitant mitral or aortic valve replacements were performed in 46 patients. There were 10 operative deaths and 6 late deaths. Actuarial survival at 9 years was $75.4 \% \pm 5.7 \%$. Prosthetic valve endocarditis occurred twice in one patient. Reoperations for tricuspid regurgitation and for concomitant procedures (maze operation and repair for leak of the mitral prosthesis) were performed in two patients. In both cases, examination of the explanted prostheses showed that the tricuspid regurgitation was the result of nonstructural dysfunction caused by fibrous pannus formation on the cusps of the ventricular side. Among the survivors, 47 patients $(92 \%)$ were in functional class I or II. Prosthetic valve function was studied by color Doppler echocardiography. Among 38 patients, tricuspid regurgitation more than grade $3 / 4$ or transprosthetic gradient more than $5 \mathrm{~mm} \mathrm{Hg}$ was found in 11. One patient had right heart failure and the others had no symptoms. In 10 years of experience with the Carpentier-Edwards pericardial xenograft, mortality and morbidity after tricuspid valve replacement were satisfactory. Echocardiographic examination revealed subclinical prosthetic dysfunction in $\mathbf{3 5 \%}$ of patients who were followed up for longer than 5 years, however, and we believe that these patients should receive careful follow-up. (J THORAC Cardiovasc Surg 1996;111:605-12)
B ecause the hemodynamic, anatomic, and hematologic characteristics of the right ventricle are different from those of the left ventricle, the clinical performance of a valve prosthesis in the tricuspid position should differ from that of a valve in the left side of the heart. Several authors have reported long-term results of the Carpentier-Edwards pericardial xenograft (CEPX), a second-generation bioprosthesis, in the aortic and mitral positions. ${ }^{1-3}$ Little is known, however, regarding the clinical performance of the CEPX in the tricuspid posi-

From the Departments of Cardiovascular Surgery, ${ }^{a}$ Cardiology, ${ }^{b}$ and Pathology, ${ }^{\mathrm{c}}$ National Cardiovascular Center, Osaka, Japan.

Received for publication Dec. 30, 1994; accepted for publication June 12, 1995.

Address for reprints: Kiyoharu Nakano, MD, Department of Cardiovascular Surgery, National Cardiovascular Center, 5-7-1 Fujisirodai Suita, Osaka 565, Japan.

Copyright $(\mathcal{C} 1996$ by Mosby-Year Book, Inc.

$0022-5223 / 96 \$ 5.00+0 \quad \mathbf{1 2 / 1 / 6 7 0 3 3}$ tion. This study represents our 10 -year experience with the CEPX for tricuspid valve replacement (TVR).

\section{Patients and methods}

Patients. From April 1985 to January 1994, 67 CEPXs were implanted in the tricuspid position in 66 patients. The prostheses were sized $27 \mathrm{~mm}$ in 4 patients, $29 \mathrm{~mm}$ in 6 patients, $31 \mathrm{~mm}$ in 38 patients, and $33 \mathrm{~mm}$ in 19 patients. An isolated procedure was performed in 13 patients. Additional procedures are shown in Table I. Concomitant mitral valve replacement (MVR), concomitant MVR and aortic valve replacement (AVR), and AVR with previous MVR and concomitant AVR were performed in 22, 20 , and 4 patients, respectively. The prostheses used in the mitral or aortic positions were mainly mechanical valve prostheses. In two patients, the CEPX was used for concomitant MVR.

TVR was performed with standard cardiopulmonary bypass and moderate systemic hypothermia. After completion of the AVR and MVR procedures, the tricuspid valve was assessed. The valve was excised, except for a segment along the conduction bundle. In most patients, the CEPX was implanted with multiple everting mattress sutures with pledgets in the tricuspid anulus, except for a 
Table I. Operative procedures

\begin{tabular}{lc}
\hline \multicolumn{1}{c}{ Procedure(s) } & No. of patients \\
\hline Isolated TVR & 13 \\
TVR with concomitant procedures & 20 \\
MVR & 1 \\
MVR + aortic repair & 1 \\
MVR + shunt closure & 19 \\
MVR + AVR & 1 \\
MVR + AVR + shunt closure & 3 \\
Mitral repair & 2 \\
AVR + mitral repair & 1 \\
AVR + shunt closure & 1 \\
AVR & 2 \\
ASD closure & 1 \\
PVR (CEPX) & 1 \\
Pericardiectomy & 1 \\
Maze &
\end{tabular}

$M V R$, Mitral valve replacement; $A V R$, aortic valve replacement; $A S D$, atrial septal defect; $P V R$, pulmonary vascular resistance.

*This patient had undergone previous MVR.

segment along the conduction bundle, where sutures were laid on the septal leaflet.

Preoperative characteristics of the study population are shown in Table II. Age at operation ranged from 8 to 71 years, with an average age of 52 years. In $94 \%$ of the patients, preoperative New York Heart Association (NYHA) functional class was III or IV. Previous cardiac operations had been performed once in 38 patients and twice in 6 patients. Previous TVR had been performed in 4 patients and previous tricuspid annuloplasty by modified DeVega or Kay methods had been performed in 17 patients. The causes of the tricuspid valve lesions were as follows: Ebstein's anomaly $(n=12)$, tricuspid regurgitation (TR) caused after the repair of congenital anomalies $(n=2)$, infectious endocarditis $(n=1)$, congenital TR $(n=1)$, and degenerative disease $(n=1)$. In 50 cases, the patients had concomitant mitral valve disease. Obvious hemodynamic tricuspid stenosis with fusion of the commissures had occurred in two patients. In the remaining cases, previous procedures for the tricuspid valve (TVR or extended tricuspid annuloplasty) had been performed or TR was caused by dilation of the tricuspid anulus and elongation of the chordae, probably as a result of mitral valve disease. Valvuloplasty was not effective in those cases.

Fifty-one patients had preoperative atrial fibrillation and two patients had implanted pacemakers before TVR. The postoperative implantation of a pacemaker was required in four patients.

Postoperative follow-up. Surviving patients have been examined in the outpatient clinic at least once every 3 months. All survivors have been followed up yearly by questionnaire. The patients who could not be contacted by questionnaire were interviewed by telephone. One patient was unavailable for follow-up. We were successful in following up $98.5 \%$ of the patients. Follow-up duration ranged from 8 months to 9 years and 6 months. Mean follow-up duration among operative survivors was 4 years and 2 months, and this follow-up totaled 283 patientyears.
Table II. Preoperative patient characteristics

\begin{tabular}{lc} 
Age & \\
Mean \pm SD (yr) & $52 \pm 14$ \\
Range (yr) & $8-71$ \\
Sex & 23 \\
Male $(n)$ & 44 \\
Female $(n)$ & \\
NYHA functional class & 4 \\
II $(n)$ & 30 \\
III $(n)$ & 33 \\
IV $(n)$ & \\
Cardiac rhythm & 14 \\
Normal sinus $(n)$ & 51 \\
Atrial fibrillation $(n)$ & 2 \\
Pacemaker $(n)$ & \\
Etiology of tricuspid lesion & 12 \\
Ebstein's anomaly $(n)$ & 3 \\
Congenital $(n)$ & 1 \\
Infectious endocarditis $(n)$ & 1 \\
Degenerative disease $(n)$ & 50 \\
Related to mitral disease $(n)$ & \\
Previous operation & 23 \\
Primary $(n)$ & 38 \\
Secondary $(n)$ & 6 \\
Tertiary $(n)$ & 4 \\
TVR $(n)$ & 17 \\
TAP $(n)$ & \\
PA systolic pressure $(42$ cases) & \\
Mean \pm SD (mm Hg) & \\
Range (mm Hg) & \\
Mean RA pressure $(37$ cases) & \\
Mean \pm SD (mm Hg) & \\
Range (mm Hg) & \\
\hline
\end{tabular}

$S D$, Standard deviation; NYHA, New York Heart Association; TAP, tricuspid annuloplasty; $P A$, pulmonary artery; $R A$, right atrial.

Definitions of events and methods of analyzing the results follow the guidelines published in this Journal. ${ }^{4}$ Thromboembolism was restricted to pulmonary embolism, excluding systemic thromboembolism. The actuarial curves were constructed by standard nonparametric Kaplan-Meier methods. Results are presented with standard error.

Anticoagulant therapy. Warfarin anticoagulation was initiated as soon as oral administration became possible. The patients with isolated TVR or concomitant MVR with the CEPX received warfarin for as long as 3 months after implantation; it was discontinued thereafter. The patients with isolated TVR and atrial fibrillation and the patients who received mechanical valves in the aortic or mitral position were maintained with long-term warfarin therapy. The criteria for an adequate anticoagulation state ranged from $254 \%$ to $454 \%$ in prothrombin time, which is equivalent to 2.9 to 1.8 times the control prothrombin time international normalized ratio.

Echocardiographic study. To evaluate prosthetic valve function, echocardiographic examination was performed in 39 patients ( $80 \%$ of all survivors who were followed up for longer than 1 year). Doppler echocardiographic scans were obtained with a phased-array two-dimensional sector scanner and color-flow imager (Toshiba SSH160A, 


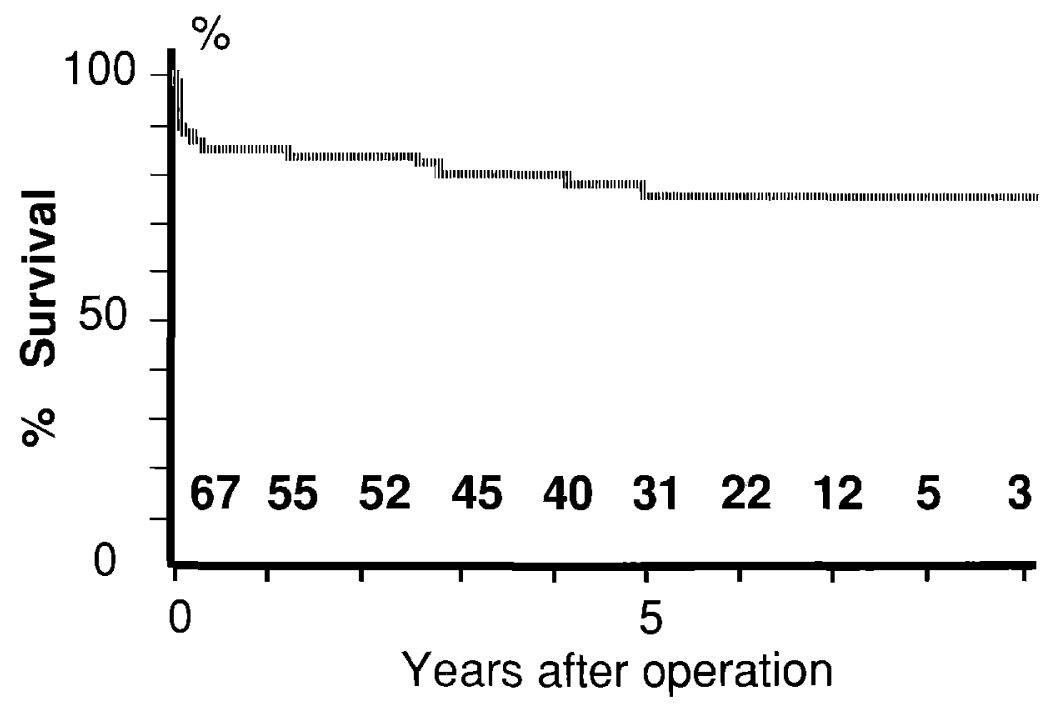

Fig. 1. Actuarial survival curve, including operative deaths. Numbers above the horizontal axis represent the number of patients eligible for analysis.

SSA270A; Toshiba America Medical Systems, Tusten, Calif.). Continuous-wave systolic and diastolic spectral velocities across the tricuspid valve were recorded axially within the color-flow signals and were measured by planimetry. The TR flow signals were examined in the four-chamber apical view in a plane that maximized the color-flow area. Distance reached by regurgitant flow signals and area of regurgitant flow signals were measured. The severity of regurgitation was graded according to the distance reached by the regurgitant signals and the area of regurgitant flow signals on a 4-point scale that was based on previous studies from this center. ${ }^{5,6}$ The mean transvalvular gradient was also estimated.

\section{Results}

The 10 operative deaths, including all hospital deaths, occurred (14.9\%). All patients had combined mitral valve disease or mitral and aortic valve disease. Seven patients had undergone previous operation. The causes of operative death were as follows: multiorgan failure after persistent congestive heart failure (eight patients), cerebral bleeding (one patient), and uncontrolled intraoperative bleeding (one patient).

There were five late deaths. The causes of late death were as follows: congestive heart failure (two patients), cerebral bleeding (one patient), prosthetic valve endocarditis (one patient), and sudden death of unknown cause (one patient). The actuarial survival after 9 years, including operative deaths, was $75.4 \% \pm 5.7 \%$ (Fig. 1).

Reoperation for tricuspid valve dysfunction and other complications was performed in two patients. One patient had undergone isolated TVR for Eb- stein's anomaly, and symptomatic paroxysmal atrial fibrillation occurred 3 years after this operation. Although the patient did not have any signs of heart failure, the echocardiographic study represented grade 3 transvalvular TR. We replaced the CEPX with another CEPX at the time of maze operation for paroxysmal atrial fibrillation (case 1). The explanted CEPX is shown in Fig. 2. There was fibrous pannus on the ventricular side and tissue overgrowth on the atrial side of the cusps, which corresponded to the location of septal and anterior leaflets of the native valve. Regurgitation occurred at the center of the prosthesis. The second patient underwent triple valve replacement 5 years after AVR and MVR. Hemolytic anemia occurred 8 years after the second operation. Echocardiographic examination revealed perivalvular leakage of the mitral prosthesis (Björk-Shiley standard valve) and grade 3 TR with restricted cuspal motion. Transvalvular gradient through the tricuspid valve prosthesis was $3 \mathrm{~mm} \mathrm{Hg}$. We repaired the leakage of the mitral prosthesis and performed TVR with a mechanical valve prosthesis (case 2). The explanted CEPX is shown in Fig. 3. There was fibrous pannus on the ventricular side of the cusps, which corresponded to the septal and the posterior leaflet of the native valve. We defined these two cases as nonstructural dysfunction. Photomicrography of the explanted valve showed dense and thick fibrous pannus on the ventricular surface of the cusp. In the middle layer of the original prosthesis, mild separation of collagen bundles and no 

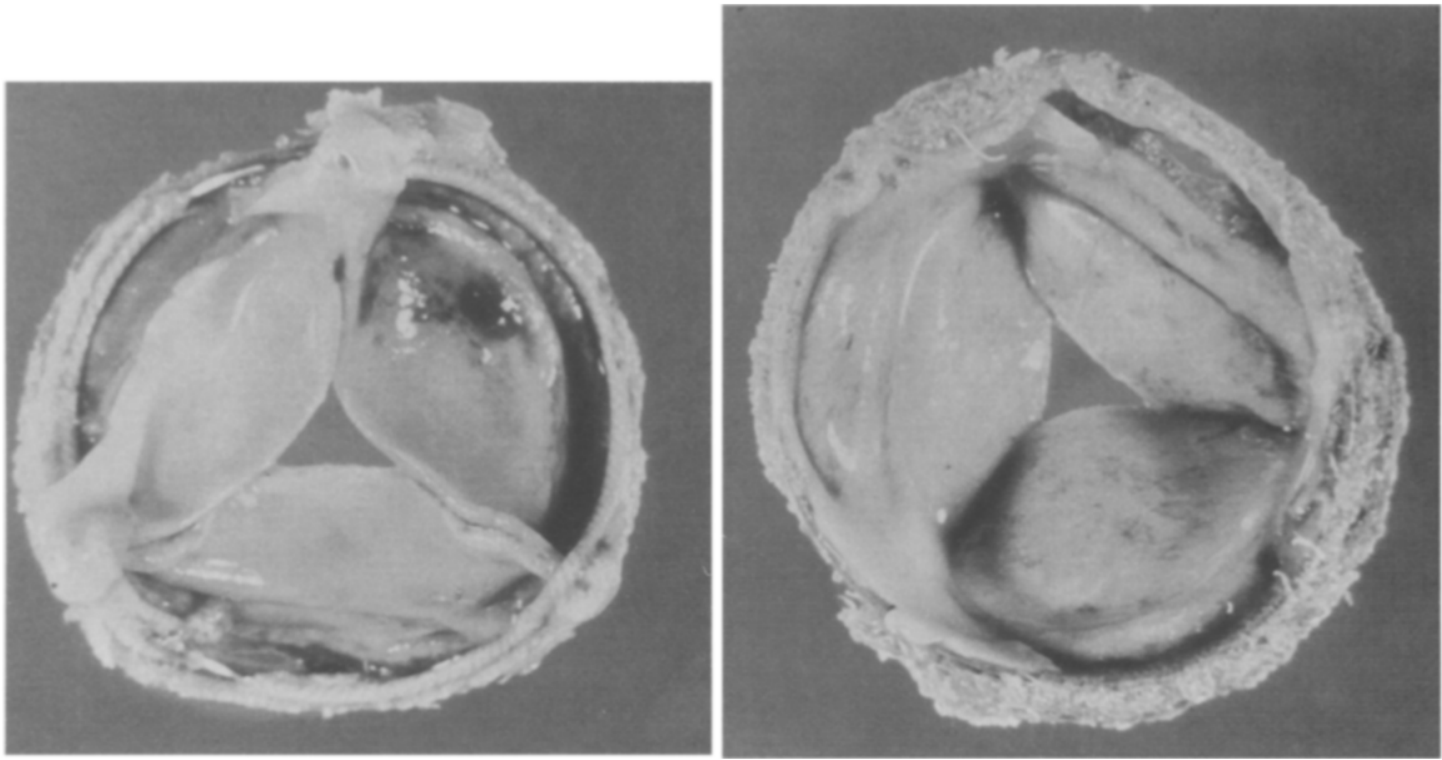

Fig. 2. Gross view of the CEPX explanted 5 years after implantation (case 1). Left panel, ventricular aspect; right panel, atrial aspect; the left side of the prosthesis was located adjacent to the intraventricular septum in both aspects. Fibrous pannus is observed on the cusps of the ventricular side, which corresponds to the location of anterior and septal leaflet of the native valve.
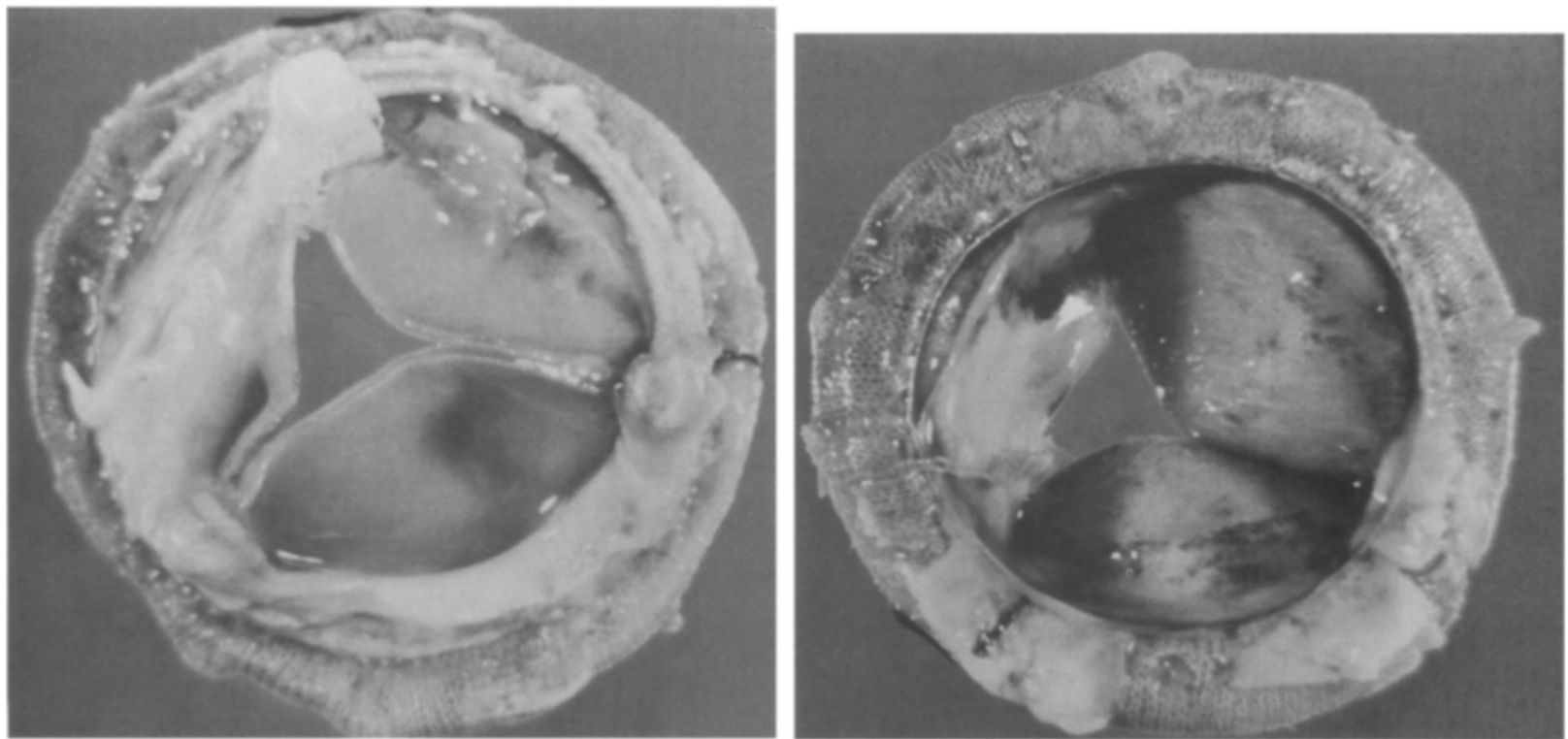

Fig. 3. Gross view of the CEPX explanted 8 years after implantation (case 2). Left panel, ventricular aspect; right panel, atrial aspect; the left side of the prosthesis was located adjacent to the intraventricular septum in both aspects. Fibrous pannus is observed on the cusps of the ventricular side, which corresponds to the septal and posterior leaflet of the native valve.

calcification were observed. Fig. 4 presents the photomicroscopic findings of the cusp in case 2.

Endocarditis of the prosthetic valve in the tricuspid position occurred twice in one patient who had undergone triple valve replacement. The event was fatal. Cerebral bleeding occurred in another patient who had undergone triple valve replacement. The aortic and mitral prostheses were St. Jude Medical 


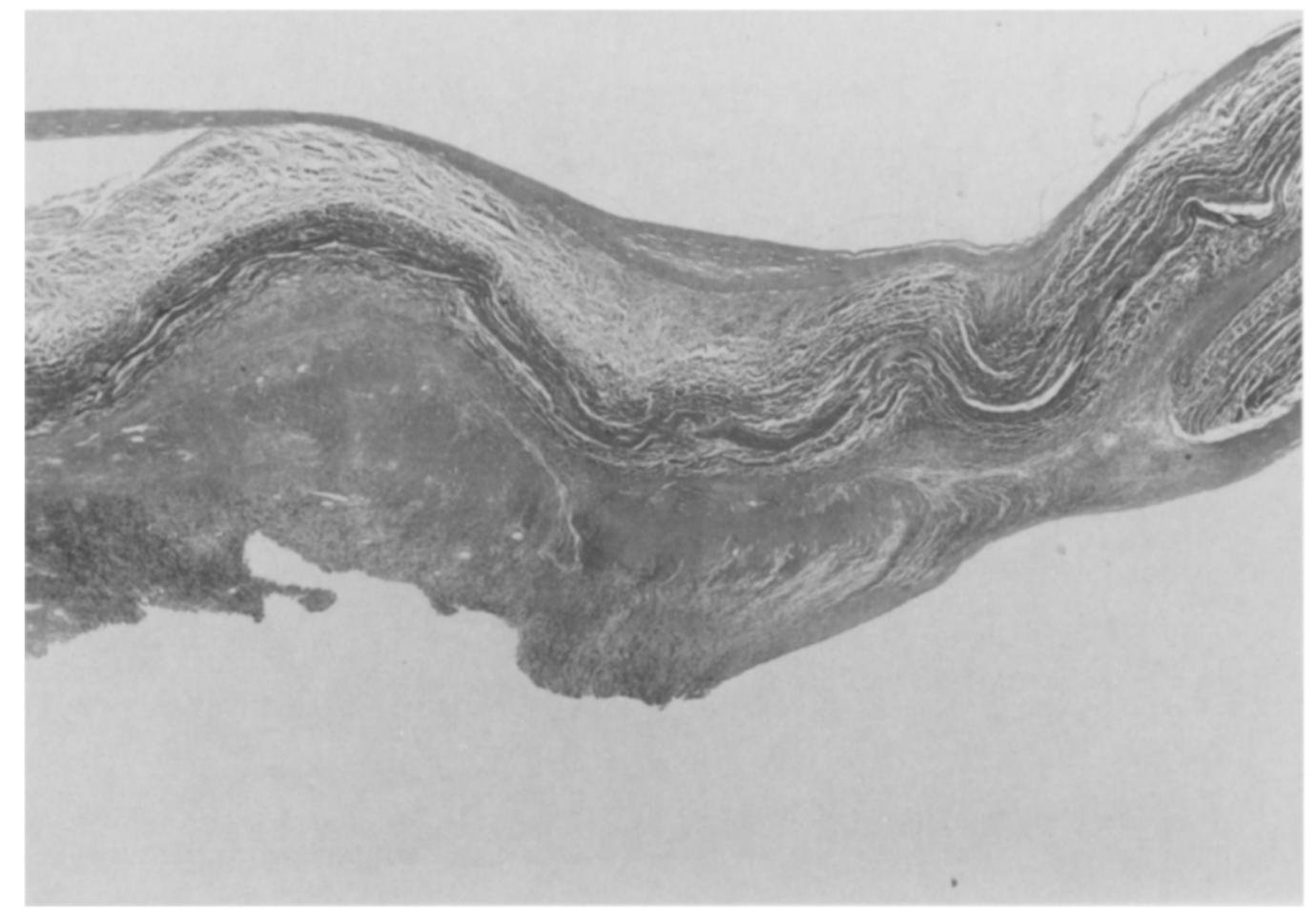

Fig. 4. Pathologic microscopic findings of the cusp in the same case shown in Fig. 2 (Masson's trichrome stain; original magnification $\times 4$ ). Top, atrial side; bottom, ventricular side. There was dense and thick fibrous pannus on the ventricular side. In the middle layer of the original bioprosthesis, no calcification and mild separation of collagen bundles were observed.

valves, and the patient received warfarin anticoagulation for the mechanical valves. This event was excluded from tricuspid valve-related events. There were no instances of structural deterioration, thrombosed valves, or pulmonary embolism. The actuarial rate of freedom from valve-related events, including nonstructural dysfunction and prosthetic valve endocarditis, was $71.3 \% \pm 20.8 \%$ at 9 years. These events and sudden unexplained deaths and operative deaths at 9 years accounted for $59.6 \% \pm 17.6 \%$ of all patients having TVR (Fig. 5).

Of the 51 patients who survived, $47(92 \%)$ were in NYHA functional class I or II. Four patients (8\%) were in NYHA functional class III.

Echocardiographic examination represented grade $3 \mathrm{TR}$ in six patients. Transprosthetic gradient of more than $5 \mathrm{~mm} \mathrm{Hg}$ with restricted cuspal motion was detected in two patients. Three patients had both TR and transprosthetic gradient of more than $5 \mathrm{~mm}$ $\mathrm{Hg}$ with restricted cuspal motion. All of these patients had been followed up for longer than 5 years, and they represented $35 \%$ of all survivors who were followed up for longer than 5 years. Two of them underwent reoperation, as mentioned previously. The other patients have been followed up medically. Only one patient had right heart failure, which was well maintained medically; the others were free of symptoms. Fig. 6 represents the actuarial rate of freedom from structural deterioration (Fig. 6,a), nonstructural dysfunction (Fig. 6, b), and nonstructural plus subclinical valve dysfunction (TR or transprosthetic gradient more than $5 \mathrm{~mm} \mathrm{Hg}$ with restricted cuspal motion detected by echocardiography; Fig. 6, c). At 9 years after operation, the actuarial rate of freedom from structural deterioration was $100 \%$, the actuarial rate of freedom from nonstructural dysfunction was $72.8 \% \pm 21.1 \%$, and the actuarial rate of freedom from nonstructural plus subclinical valve dysfunction was $24.3 \% \pm$ $20.0 \%$.

\section{Discussion}

TVR is not a common procedure because valve repair is preferred for the treatment of TR. In the same period as this series, tricuspid valvuloplasty, including 27 ring annuloplasty procedures, was per- 


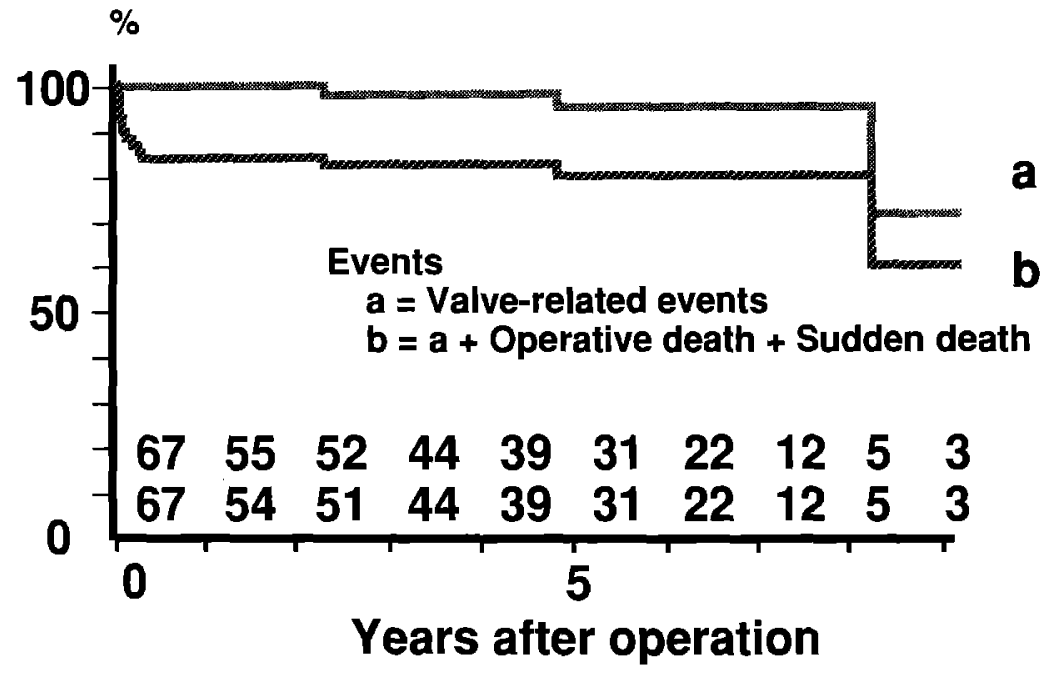

Fig. 5. Actuarial rates for freedom from valve-related events (a) and valve-related events plus operative deaths and sudden deaths $(b)$.

formed in 410 patients. In the patients who required TVR, the organic change of the tricuspid valve was prominent or TVR or tricuspid annuloplasty had already been performed.

The choice of a bioprosthesis for TVR has been advocated for two reasons: (1) A valve can be expected to be more durable in a low-pressure chamber than in the systemic circulation. (2) A high rate of valve thrombosis has been reported for mechanical prostheses in the tricuspid position.

In the literature on long-term results of TVR with bioprostheses, several authors have reported on the first-generation bioprostheses. ${ }^{7-9}$ Guerra and colleagues $^{7}$ reviewed the cases of 45 patients with 14-year follow-up. Actuarial freedom from structural deterioration of a Hancock tricuspid porcine bioprostheses at 14 years is $68 \% \pm 13 \%{ }^{8}$ Kawachi and associates ${ }^{8}$ also reported excellent durability of the Hancock porcine bioprosthesis in the tricuspid position. Their actuarial freedom from structural valve failure at 10 years was $94 \% \pm 6 \%$. Eng and colleagues $^{9}$ reported long-term results of the TVR with the Ionescu-Shiley valve in 73 patients. In their mean 9.6 years of follow-up (range from 4 to 18 years), primary tissue failure occurred in only one patient. Seventy-nine percent of the survivors were in NYHA functional class I or II. These articles document excellent durability of bioprostheses in the tricuspid position.

The CEPX is a second generation bioprosthesis that uses bovine pericardium tanned with glutaraldehyde. Because this feature, together with computer- aided cusp and stent design, resulted in excellent wear-testing performance compared with other bioprostheses, the CEPX should be more durable than other bioprostheses. ${ }^{10}$ Several authors demonstrated excellent clinical performance of this prosthesis in the aortic position ${ }^{1-3}$ and even in the mitral position. ${ }^{3}$ In these series, no cusp tear occurred for as long as 7 years; cusp tear did occur in series with the IonescuShiley pericardial valve. ${ }^{11,12}$ These results suggest that more durability can be expected of the CEPX than of first-generation bioprostheses.

A high incidence of valve thrombosis after TVRs with mechanical valves has been reported. The type of prosthesis used in most of these studies was the Björk-Shiley tilting-disc valve. ${ }^{13-16}$ Regarding the bileaflet valve, currently used worldwide, the principal author (K.N.) saw 39 adult cases of TVR with the St. Jude Medical valve in another institution. ${ }^{17}$ In the 14-year follow-up period, there was only one thrombosed valve $(0.67 \%$ per patient-year) under conditions of proper anticoagulation. These results suggest that the incidence of valve thrombosis after TVR with the low-profile St. Jude Medical valve may be lower than that with the Björk-Shiley valve. In that series, the actuarial rate of freedom at 14 years from all operative deaths, all valve-related deaths (including sudden unexpected death), and all nonfatal valve-related morbid events was $80.5 \% \pm$ $6.7 \%$. In the study reported here, the actuarial rate of freedom at 10 years from the same events was $58.2 \% \pm 17.3 \%$. Both curves were not statistically significant. 


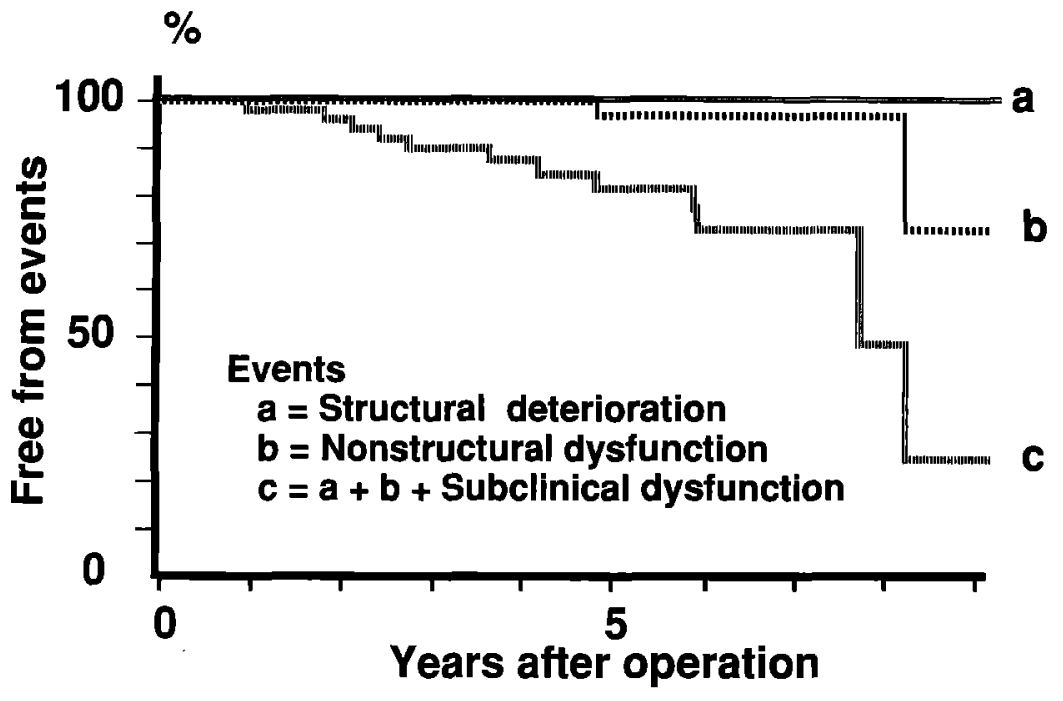

Fig. 6. Actuarial rates for freedom from structural deterioration (a), nonstructural dysfunction $(b)$, and nonstructural dysfunction plus subclinical dysfunction detected by Doppler echocardiography $(c)$.

The pathologic findings of both explanted CPEX valves demonstrated fibrous pannus formation in the ventricular side of the cusps, which made the cusps shrink and caused TR. The macroscopic findings did not demonstrate calcification and sclerotic change of the cusps. Cohen and colleagues ${ }^{18}$ examined Hancock porcine bioprostheses implanted simultaneously in six patients and explanted 62 to 140 months later. The degenerative changes were more extensive for the prostheses in the mitral position than for those in the tricuspid position. Thrombus formation was observed on the ventricular aspects of the bioprosthetic cusps in one valve in the mitral position and in four valves in the tricuspid position. Guerra and colleagues ${ }^{7}$ reported morphologic examination of explanted porcine bioprostheses in their experience with nine reoperation cases. The prostheses explanted from the tricuspid position had lower degrees of calcification and less severe structural change than did those simultaneously explanted from the mitral position. The finding peculiar to the tricuspid position, not observed in explants from the mitral position, was the presence of fibrous pannus on the ventricular side, growing into one or more sinuses and impairing pliability of the corresponding cusp. These findings correspond with those observed in our series.

The pannus formation, interpreted as organized thrombotic material, may be related to the anatomic and hemodynamic characteristics of the right ventricle. Because the right ventricle is wedge shaped in configuration, the prosthetic cusps adjacent to the sewing cuff easily might touch the remnant of the native valve and subvalvular component of the tricuspid valve, resulting in thrombus formation and tissue overgrowth. Further, lower pressure and lower flow velocity of blood in the right ventricle could increase the thrombogenicity of the xenograft.

Even though the patients had not reported any of the symptoms of heart failure, echocardiographic studies revealed a high incidence of TR and transvalvular gradients. In most cases of TR, the regurgitant flow was detected near the center of the prosthesis and restricted motion was observed in one or two cusps. Echocardiographic information is limited in clearly explaining the cause of these subclinical valve dysfunctions. The study of explanted CEPX valves in this series, however, suggests that most of the tricuspid bioprosthetic dysfunction in the intermediate period after operation may be caused by pannus formation on the cusps of the bioprosthesis, not by degenerative changes of the cusps.

Of the patients in whom TR or transprosthetic gradient was detected by echocardiography (nine, excluding two patients who underwent reoperation), eight were in NYHA functional class I or II. One patient had a history of congestive heart failure 6 years after MVR and TVR. Since then, however, this heart failure has been well controlled medically. None of these nine patients required replacement of the tricuspid CEPX.

In conclusion, in our 10-year experience with the CEPX, the mortality and morbidity after TVR were satisfactory. Echocardiographic examination re- 
vealed subclinical prosthetic dysfunction in $35 \%$ of patients who were followed up for longer than 5 years, however, and we believe that these patients need careful follow-up.

\section{REFERENCES}

1. Perier $P$, Mihaileanu $S$, Fabiani J, et al. Long-term evaluation of the Carpentier-Edwards pericardial valve in the aortic position. J Cardiac Surg 1991;6:589-94.

2. Frater RWM, Salomon NW, Rainer WG, Cosgrove DM 3rd, Wickham E. The Carpentier-Edwards pericardial aortic valve: intermediate results. Ann Thorac Surg 1992;53:764-71.

3. Meyns B, Szecsi J, Flameng W, Daenen W. Aortic and mitral valve replacement with the Carpentier-Edwards pericardial bioprosthesis: mid-term clinical results. J Heart Valve Dis 1993;2:66-70.

4. Edmunds LH Jr, Clark RE, Cohn LH, Miller DC, Weisel RD. Guidelines for reporting morbidity and mortality after cardiac valvular operations. J THORAC CARDIOvasC SURG 1988;96:351-3.

5. Miyatake K, Okamoto M, Kinoshita N, et al. Evaluation of tricuspid regurgitation by pulsed Doppler and two-dimensional echocardiography. Circulation 1982;66;777-84.

6. Misawa $\mathrm{T}$, Miyatake $\mathrm{K}$, Izumi $\mathrm{S}$, et al. Assessment of tricuspid regurgitation by real-time two-dimensional Doppler flow imaging. Jpn J Med Ultrasonics Proc 1985;463-4.

7. Guerra F, Bortolotti U, Thiene G, et al. Long-term performance of Hancock porcine bioprosthesis in the tricuspid position: a review of forty-five patients with fourteen-year follow-up. J THorac Cardiovasc Surg 1990;99;838-45.

8. Kawachi Y, Tominaga R, Hisahara M, Nakashima A, Yasui $H$, Tokunaga $K$. Excellent durability of the Hancock porcine bioprosthesis in the tricuspid position. J THORAC CARDIOVASC SURG 1992;104:1561-6.
9. Eng J, Ravichandran PS, Kay PH, Murday AJ. Ann Thorac Surg 1990;51:200-3.

10. Gabbay S, Kadam P, Factor S, Cheung TK. Do heart valve bioprostheses degenerate for metabolic or mechanical reasons? J THORAC CARDIOvasC Surg 1988;95:208-15.

11. Gabbay S, Bortolotti U, Wasserman F, Tindel N, Factor SM, Frater RW. Long-term follow-up of the Ionescu-Shiley mitral pericardial xenograft. J THORAC CARDIOVASC SURG 1984;88: 758-63.

12. Walley VM, Keon WJ. Patterns of failure in Ionescu-Shiley bovine pericardial bioprosthetic valves. J THORAC CARDIOVASC SURG 1987;93:925-33.

13. Bourdillon PD, Chaired GP. Malfunction of Björk-Shiley valve prosthesis in tricuspid position. Br Heart J 1976;38: 1149-53.

14. Thorburn CW, Morgan JJ, Shanahan MX, Chang VP. Longterm results of tricuspid valve replacement and the problem of prosthetic valve thrombosis. Am J Cardiol 1983;51:112832.

15. Weerasena N, Spyt TJ, Pye M, Bain WH. Clinical evaluation of Björk-Shiley disc valve in the tricuspid position. Eur J Cardiothorac Surg 1990;4:19-23.

16. Boskovic D, Elezovic I, Boskovic D, et al. Late thrombosis of the Björk-Shiley tilting disc valve in the tricuspid position: thrombolytic treatment with streptokinase. J Thorac Cardiovasc Surg 1986;91:1-8.

17. Nakano K, Koyanagi H, Hashimoto A, Ohtsuka G, Nojiri C. Tricuspid valve replacement with bileaflet St. Jude Medical valve prosthesis. J THORAC CARDIOvASC SURG 1994;108:88892.

18. Cohen SR, Silver MA, McIntosh CL, Roberts WC. Comparison of late (62 to 140 months) degenerative changes in simultaneously implanted and explanted porcine (Hancock) bioprostheses in the tricuspid and mitral valve positions in six patients. Am J Cardiol 1984;53:1599-602.

\section{Availability of JournaL back issues}

As a service to our subscribers, copies of back issues of THE Journal of THORACIC AND CARDIOVASCULAR SURGERY for the preceding 5 years are maintained and are available for purchase from the publisher, Mosby-Year Book, Inc., at a cost of $\$ 13.50$ per issue. The following quantity discounts are available: $25 \%$ off on quantities of 12 to 23 , and one third off on quantities of 24 or more. Please write to Mosby-Year Book, Inc., Subscription Services, 11830 Westline Industrial Drive, St. Louis MO 63146-3318, or call $800-453-4351$ or 314-453-4351 for information on availability of particular issues. If unavailable from the publisher, photocopies of complete issues are available from University Microfilms International, 300 N. Zeeb Rd., Ann Arbor, MI 48106, 313-761-4700. 